\title{
IMPLEMENTASI PROGRAM BADAN PENYELENGGARA JAMINAN SOSIAL KETENAGAKERJAAN BAGI PEKERJA DI TPA DESA TEMESI KABUPATEN GIANYAR*
}

\author{
Oleh: \\ Gusti Ayu Krisma Aryastuti** \\ I Ketut Markeling*** \\ Program Kekhususan Hukum Bisnis \\ Fakultas Hukum Universitas Udayana
}

\begin{abstract}
ABSTRAK
Pekerja dalam pembangunan nasional memiliki peranan penting sehingga dengan meningkatnya tantangan serta resiko yang dihadapinya maka perlu diberikan perlindungan sebagai dasar untuk memenuhi kebutuhan minimum bagi pekerja. Adakalanya perusahaan tidak memberikan jaminan sosial ketenagakerjaan sebagai perlindungan terhadap pekerja. Maka dari itu perlunya perlindungan bagi pekerja dari pemberi kerja, sehingga perlu mendapat perhatian dari pemberi kerja agar sesuai dengan ketentuan yang berlaku. Dengan adanya kejadian tersebut, maka perlu diteliti mengenai implementasi program Badan Penyelenggara Jaminan Sosial Ketenagakerjaan di Tempat Pembuangan Akhir Desa Temesi Kabupaten Gianyar. Penelitian yang digunakan adalah penelitian yuridis empiris dengan menggunakan Pendekatan Fakta. Data yang digunakan berupa data primer dan data sekunder. Pengumpulan data dilakukan melalui studi dokumen dan wawancara. Hasil penelitian diolah secara kualitatif. Melalui data yang diperoleh dari hasil penelitian maka diketahui bahwa Tempat Pembuangan Akhir Temesi telah mendaftarkan pekerja tetap maupun pekerja kontrak tetapi bagi pekerja harian lepas belum terdaftar dalam pengimplementasian program Badan Penyelenggara Jaminan Sosial Ketenagakerjaan
\end{abstract}

* Penulisan ini berjudul Implementasi Program Badan Penyelenggara Jaminan Sosial Ketenagakerjaan bagi Pekerja di TPA Desa Temesi Kabupaten Gianyar, yang merupakan makalah ilmiah di luar ringkasan skripsi.

** Penulis pertama dalam penulisan makalah ilmiah ini ditulis oleh Gusti Ayu Krisma Aryastuti, merupakan mahasiswa Fakultas Hukum Universitas Udayana. Korespondensi: krismaaryastuti@gmail.com.

*** Penulis kedua dalam penulisan makalah ilmiah ini ditulis oleh I Ketut Markeling, SH., MH., selaku Pembimbing Akademik dari penulis pertama di Fakultas Hukum Universitas Udayana. 
oleh karena itu harus mengacu pada ketentuan yang berlaku untuk perlindungan pekerja. Adapun hambatan terhadap implementasi program Badan Penyelenggara Jaminan Sosial Ketenagakerjaan yakni ketidakjelasan perpanjangan masa kerja terhadap pekerja kontrak maupun pekerja harian lepas karena masih banyaknya pegawai tetap yang mengisi posisi jabatan.

\title{
Kata Kunci: Implementasi, Perlindungan, Pekerja
}

\begin{abstract}
Workers in national development have an important role so that with the increasing challenges and risks they face, it is necessary to provide protection as a basis for meeting minimum needs for workers. Sometimes companies do not provide employment social security as protection for workers. Therefore the need for protection for workers from employers, so that the attention of the employer needs to be in accordance with applicable regulations. With this incident, it is necessary to examine the implementation of the Employment Social Security Organizer Agency program at the Final Disposal Site Village Temesi Gianyar Regency. The research used is empirical juridical research using the Fact Approach. Data used in the form of primary data and secondary data. Data collection is done through document studies and interviews. The results of the study were processed qualitatively. Through the data obtained from the results of the study, it is known that the Temesi the Final Disposal Site has registered permanent workers and contract workers, but for casual daily workers not registered in the implementation of the Employment Social Security Organizer Agency program, therefore it must refer to the applicable provisions for worker protection. The obstacles to the implementation of the Employment Social Security Organizer Agency program are the unclear extension of the working period for contract workers and casual daily workers because there are still many permanent employees who fill positions.
\end{abstract}

\section{Keywords: Implementation, Protection, Workers}

\section{PENDAHULUAN}

\subsection{Latar Belakang}

Tempat Pembuangan Akhir (TPA) ialah salah satu tempat mata pencaharian para pekerja yang merupakan penduduk di wilayah sekitaran TPA untuk melakukan pekerjaan guna 
memperolah penghasilan. Tempat Pembuangan Akhir (TPA) juga menjadi salah satu sektor penting dalam rangka memenuhi kebutuhan hidup masyarakat, khususnya para pekerja. Atas dasar keperluan sehari-hari yang tinggi untuk memenuhi kebutuhan hidup itulah yang mendorong orang-orang menjalankan pekerjaan mengandalkan sampah.

Keadaan seperti inilah yang akhirnya menimbulkan tantangan dan resiko bagi para pekerja sehingga perlu mendapatkan perlindungan, pemeliharaan, serta peningkatan kesejahteraan untuk perlindungan dasar yang berguna dalam memenuhi kebutuhan hidup minimum. ${ }^{1}$ Hal ini bertujuan dalam menjamin hak dasar dan menjamin keselamatan, kesehatan serta perlakuan tanpa diskriminasi atas dasar apapun guna mewujudkan kesejahteraan pekerja beserta keluarganya. Menurut salah satu pendapat sarjana hukum yakni Zaeni Azyhadieyang membagi menjadi 3 (tiga) macam perlindungan pekerja antara lain:

1) Perlindungan teknis disebut sebagai perlindungan keselamatan kerja karena bertitik tolak pada upayaupaya pencegahan bahaya kecelakaan ketika bekerja guna melindungi pekerja.

2) Perlindungan sosial disebut sebagai perlindungan kesehatan kerja karena bertitik tolak pada upaya kemasyarakatan guna memungkinkan pekerja mengenyam serta khususnya sebagai anggota masyarakat dan anggota keluarga.

3) Perlindungan ekonomis disebut sebagai perlindungan jaminan sosial karena bertitik tolak pada upaya-upaya

1. Ikhwan Fahrojih, 2016, Hukum Perburuhan: Konsepsi, Sejarah, dan Jaminan Konstitusional, Setara Press, Malang, h. 30. 
pemberian pendapatan yang cukup dalam memenuhi kebutuhan sehari-hari terhadap pekerja. ${ }^{2}$

Berdasarkan Undang-Undang Nomor 24 Tahun 2011 tentang Badan Penyelenggara Jaminan Sosial Pasal 14 yang menyatakan bahwa setiap orang, termasuk orang asing yang bekerja paling singkat 6 (enam) bulan di Indonesia, wajib menjadi Peserta program Jaminan Sosial. Dengan adanya ketentuan tersebut maka setiap pekerja wajib terdaftar sebagai peserta dalam program jaminan sosial karena perlindungan teknis, sosial dan ekonomis bagi pekerja adalah tanggung jawab dari perusahaan, maka perlu diperhatikan berdasarkan yang telah diatur sesuai peraturan perundang-undangan yang berlaku. TPA Desa Temesi telah melaksanakan program BPJS Ketenagakerjaan dengan mendaftarkan para pekerja tetap maupun pekerja kontrak sedangkan pekerja harian lepas yang bekerjadi TPA Temesi tidak terdaftar sebagai peserta BPJS Ketenagakerjaan. Sehingga hal ini bertentangan dengan Pasal 14 Undang-Undang Nomor 24 Tahun 2011 tentang Badan Penyelenggara Jaminan Sosial.

Untuk mengetahui pengimplementasian dari program BPJS Ketenagakerjaan, maka penulis akan melakukan penelitian di Desa Temesi Kabupaten Gianyar guna memperoleh informasi yang dapat membantu penulis untuk membahas lebih lanjut mengenai implementasi serta hambatan dari program Badan Penyelenggaraan Jaminan Sosial Ketenagakerjaan bagi pekerja TPA dalam Jurnal yang berjudul "Implementasi Program Badan Penyelenggara Jaminan Sosial Ketenagakerjaan Bagi Pekerja di TPA Desa Temesi Kabupaten Gianyar".

2. A.A. Ayu Indah Mahardani, 2017, Perlindungan Hukum Keselamatan Kerja Pekerja Tukang Sapu Pada Dinas Kebersihan dan Pertamanan Kabupaten Badung, Kertha Semaya, Vol. 05, No. 02, h. 3. 


\subsection{Rumusan Masalah}

1. Bagaimana implementasi dari program Badan Penyelenggara Jaminan Sosial Ketenagakerjaan bagi pekerja di TPA Desa Temesi Kabupaten Gianyar?

2. Hambatan-hambatan apa saja yang dihadapi dalam implementasi program Badan Penyelenggara Jaminan Sosial Ketenagakerjaan bagi pekerja di TPA Desa Temesi Kabupaten Gianyar?

\subsection{Tujuan Penulisan}

Adapun tujuan dari penulisan karya ilmiah ini adalah untuk mengetahui dan memahami tentang implementasi dari program Badan Penyelenggara Jaminan Sosial Ketenagakerjaan bagi pekerja di TPA Desa Temesi Kabupaten Gianyar serta untuk mengetahui dan memahami hambatan-hambatan yang dihadapi dalam implementasi program Badan Penyelenggara Jaminan Sosial Ketenagakerjaan bagi pekerja di TPA Desa Temesi Kabupaten Gianyar.

\section{ISI MAKALAH}

\subsection{Metode Penelitian}

Penulis menggunakan jenis penelitian hukum yuridis empiris karena pada dasarnya penelitian yuridis empiris dalam melakukan penganalisisan harus dilakukan dengan cara mengkombinasikan data-data yang ada yakni dengan melihat secara langsung bagaimana hukum bekerja di lingkungan masyarakat, sekaligus melihat hukum tersebut secara nyata. ${ }^{3}$ Dalam penelitian empiris ini, jenis data yang dipergunakan penulis yakni berupa data primer yang bersumber dari penelitian secara langsung di lapangan serta data sekunder yang bersumber dari

3. Ashsofa Burhan, 2004, Metode Penelitian Hukum, PT Rineka Cipta, Jakarta, h. 28. 
penelitian kepustakaan. ${ }^{4}$ Untuk jenis pendekatan yang digunakan yaitu jenis Pendekatan Fakta (The Fact Approach). Teknik pengumpulan data dilakukan melalui studi dokumen dan wawancara, kemudian setelah itu hasil penelitian akan diolah secara kualitatif.

\subsection{Hasil dan Analisis}

\subsubsection{Implementasi Program Badan Penyelenggara Jaminan Sosial Ketenagakerjaan Bagi Pekerja di TPA Desa Temesi Kabupaten Gianyar}

Pelaksanaan dalam pemberian perlindungan terhadap tenaga kerja dalam menghadapi berbagai tantangan bahkan resiko di bidang ekonomi serta sosial yang dapat terjadi ketika pekerja melakukan suatu pekerjaan seperti contoh terjadinya kecelakaan kerja yang bisa mengganggu kinerja pekerja dalam peningkatan produktivitas sehinga sangat perlu mewujudkan ketenangan dalam bekerja yang harus diwujudkan oleh setiap pengusaha sehingga dapat meningkatkan produktivitas pada perusahaan. Definisi pekerja/buruh tertuang dalam ketentuan Pasal 1 angka 3 Undang-Undang Nomor 13 Tahun 2003 tentang Ketenagakerjaan yang berarti setiap orang yang bekerja dengan menerima upah atau imbalan dalam wujud lain. Jadi berdasarkan definisi diatas maka dapat dijelaskan bahwa tenaga kerja yang sudahbekerjalah yang dapat disebut dengan pekerja atau buruh. Pengertian tenaga kerja ialah setiap orang yang memiliki kemampuan melaksanakan suatu pekerjaan sehingga dapat menghasilkan suatu barang ataupun jasa baik yang berguna untuk memenuhi kebutuhan sendiri atau pribadi maupun untuk kebutuhan dari masyarakat

4. Amiruddin dan H. Zainal Asikin, 2016, Pengantar Metode Penelitian Hukum, Cet. IX, Rajawali Pers, Jakarta, h. 31. 
itu sendiri. ${ }^{5}$ Ketentuan mengenai kesejahteraan pekerja terdapat dalam Pasal 99 ayat (1) dan ayat (2) Undang-Undang Nomor 13 Tahun 2003 tentang Ketenagakerjaan yang mengatur mengenai kesejahteraan pekerja beserta keluarganya. Hal yang diatur pada pasal ini adalah berhaknya mendapatkan jaminan sosial tenaga kerja yang diperuntukkan bagi pekerja atau buruh beserta keluarganya sekaligus dilakukan berdasarkan pada peraturan perundang-undangan yang berlaku terkait jaminan sosial tenaga kerja tersebut. Kemudian berdasarkan pada Pasal 14 UndangUndang Nomor 24 Tahun 2011 tentang Badan Penyelenggara Jaminan Sosial yang menyatakan bahwa setiap orang, termasuk orang asing yang bekerja paling singkat 6 (enam) bulan di Indonesia, wajib menjadi Peserta program Jaminan Sosial. Undang-Undang ini telah mengatur secara lebih mengkhusus terkait jaminan sosial yang diberikan terhadap pekerja yang memiliki pekerjaan di wilayah Indonesia.

Pemberian perlindungan terhadap para tenaga kerja yang diwujudkan dalam bentuk santunan seperti halnya pemberian uang sebagai pengganti dari sebagian pendapatan yang berkurang maupun hilang sekaligus suatu pelayanan sebagai akibat dari peristiwa maupun suatukeadaan yang terjadi pada tenaga kerja seperti halnya sakit, kecelakaan kerja, hamil, bersalin, hari tua, jaminan pensiun serta meninggal dunia yang merupakan pelaksanaan dari program Badan Penyelenggara Jaminan Sosial Ketenagakerjaan yang memberikan perlindungan bagi pekerja dalam melaksanakan pekerjaannya. ${ }^{6}$ Tujuan dari pemberian perlindungan terhadap pekerja guna menjamin berlangsungnya

5. I Ketut Hendra Winata, 2013, Perlindungan Hukum Terhadap Pekerja Setelah Terjadinya Pemutusan Hubungan Kerja Secara Sepihak Pada Hotel Four Seasons Resort Bali di Sayan, Kertha Wicara, Vol. 2, No. 1, h. 2.

6. Lalu Husni, 2014, Pengantar Hukum Ketenagakerjaan, Cet. XII, PT Raja Grafindo Persada, Jakarta, h. 151-152. 
suatu sistem hubungan kerja yang harmonis tanpa adanya suatu tekanan dari pihak yang lebih kuat terhadap pihak yang lebih lemah. Tanpa adanya suatu jaminan terhadap kehidupan yang pasti, serta peningkatan terhadap kualitas pekerja maupun perlindungan bagi para tenaga kerja yang harus berdasarkan dan sesuai dengan harkat martabat manusia yangmenyebabkan tidak akan mungkin tercapainya perlindungan bagi para pekerja, maka dari itu perlindungan terhadap pekerja dapat tercapai dengan adanya jaminan hidup yang pasti.

Berdasarkan keterangan dari hasil wawancara dengan I Wayan Cakra selaku Manager Yayasan Pemilahan Sampah Temesi, beliau mengatakan terdapat beberapa jenis tenaga kerja di TPA Desa Temesi yaitu sebagai berikut: pekerja tetap, pekerja kontrak, dan pekerja harian lepas. TPA Desa Temesi memberikan perlindungan terhadap para pekerja sesuai dengan peraturan perundang-undangan yang berlaku yakni Undang-Undang Nomor 13 Tahun 2003 tentang Ketenagakerjaan serta sesuai dengan perjanjian kerja antara pihak TPA Desa Temesi dengan pekerja, dimana pihak TPA Temesi memberikan perlindungan sesuai dengan hak-hak para pekerja. TPA Temesi telah mendaftarkan seluruh pekerja tetap maupun kontrak dalam program pemerintah baik BPJS Ketenagakerjaan serta BPJS Kesehatan. Jika terdapat ketentuan-ketentuan antara pihak TPA Temesi dengan pekerja diluar perundang-undangan misalkan saja seperti masih adanya tenaga kerja yang belum terdaftar dalam program BPJS maka sebelumnya sudah ada perjanjiankerja antara pihak TPA Temesi dengan pekerja, pihak TPA Temesi tetap akan memberikan perlindungan serta hak-hak pekerjasesuai dengan ketentuan yang berlaku. 
Berdasarkan keterangan Sriasih selaku staf Yayasan Pemilahan Sampah Temesi, perlindungan ekonomis atau upah yang diberikan oleh pihak TPA Temesi sesuai dengan Upah Minimum Kabupaten/Kota (UMK). Sebagai pegawai kontrak Sriasih juga sudah di daftarkan dalam program BPJS, baik BPJS Kesehatan maupun BPJS Ketenagakerjaan serta berdasarkan wawancara dengan Gusti Nyoman Karniawati selaku pegawai kontrak dalam pemilahan sampah mengatakan bahwa terdapat perlindungan teknis yang diberikan oleh pihak TPA Temesi, yakni misalnya memberikan pelatihan dengan alat-alat yang sudah tersedia di TPA Temesi sekaligus cara menggunakannya terkait dalam menanggulangi maupun mencegah apabila terjadi suatu bencana alam seperti kebakaran, hal ini disebabkan oleh sampah yang menggunung terus-menerus tepapar oleh sinar matahari, sehingga dapat membahayakan lahan pertanian warga karena lokasi penampungan sampah yang dekat dengan areal persawahan. Terkait dengan perlindungan terhadap pekerja TPA Temesi, jika dikaitkan dengan 3 (tiga) macam perlindungan tenaga kerja yang dipaparkan menurut Zaeni Asyhadie, maka yang sudah diimplementasikan yakni:

1. Perlindungan teknis yakni dengan diberikannya pelatihan kerja agar dapat menyesuaikan dengan lingkungan tempat kerja, sekaligus pelatihan simulasi dalam hal menanggulangi apabila terjadi bencana alam. Berdasarkan keterangan yang diperoleh dari hasil wawancara dengan Gusti Nyoman Karniawati yang menjabat sebagai pegawai kontrak pemilahan sampah.

2. Perlindungan sosial yakni dengan menjalankan program BPJS Ketenagakerjaan sekaligus BPJS Kesehatan dengan cara mendaftarkan para pekerja tetap maupun pekerja 
kontrak yang ada di lingkungan TPA Temesi. Berdasarkan keterangan yang diperoleh dari hasil wawancara dengan I Wayan Cakra yang menjabat sebagai Manager Yayasan Pemilahan Sampah Temesi.

3. Perlindungan ekonomis yakni dengan memberikan para pekerja upah pekerja yang sudah sesuai dengan Upah Minimum Kabupaten/Kota (UMK). Berdasarkan keterangan yang diperoleh dari hasil wawancara dengan Sriasih yang menjabat sebagai staf Yayasan Pemilahan Sampah Temesi.

Jadi berdasarkan hasil wawancara yang diperoleh dengan pihak TPA Temesi, maka sudah diimplementasikannya program BPJS Ketenagakerjaan sekaligus BPJS Kesehatan dengan telah didaftarkannya para pekerja agar mendapatkan perlindungan dalam bekerja. Sedangkan terkait dengan pekerja harian lepas yang belum didaftarkan dalam program BPJS oleh pihak TPA Temesi dapat menggunakan kotak P3K (Pertolongan Pertama Pada Kecelakaan) yang tersedia di TPA Temesi apabila terjadinya suatu kecelakaan kerja yang menimpa pekerja harian lepas. Terkait dengan hal pertanggung jawaban dari pihak TPA Temesi terhadap para pekerja apabila sampai terjadinya suatu kecelakaan kerja di saat pekerja melakukan kewajibannya ketika bekerja, sehingga pengusaha dalam hal ini akan menanggung beban secara materiil yakni dengan pemberian penggantian terkait biaya yang ditimbulkan akibat terjadinya suatu kecelakaan kerja. ${ }^{7}$ Selain itu, juga diberikannya pelatihan teknis kepada para pekerja seperti simulasi dalam penggunaan alat-alat yang tersedia di TPA Temesi dalam menanggulangi apabila terjadinya suatu bencana alam.

7. Soedarjadi, 2008, Hukum Ketenagakerjaan di Indonesia, Pustaka Yustisia, Yogyakarta, h. 53. 
Mengacu pada ketentuan Pasal 17 Undang-Undang Nomor 24 Tahun 2011 tentang Badan Penyelenggara Jaminan Sosial, Pasal 59 Undang-Undang Nomor 44 Tahun 2015 tentang Jaminan Kecelakaan Kerja dan Jaminan Kematian, kemudian ketentuan Pasal 34 Undang-Undang Nomor 45 Tahun 2015 tentang Program Jaminan Pensiun serta ketentuan dari Pasal 33 Undang-Undang Nomor 46 Tahun 2015 tentang Program Jaminan Hari Tua, yang menegaskan bahwa apabila para pemeberi kerja yang dalam hal ini adalah sebagai pengusaha tidak mendaftarkan para pekerja yang termasuk sebagai pekerja harian lepas maka dapat diberikan ganjaran berupa sanksi administratif yakni sebagai berikut:

1) Teguran tertulis;

Sanksi administratif ini termasuk sanksi ringan yang diberikan kepada pengusaha yakni berupa teguran tertulis seperti pemberian surat peringatan pada tahap awal pemberian sanksi.

2) Denda; dan/atau;

Sanksi administratif ini termasuk sanksi sedang yang diberikan kepada pengusaha yakni berupa pembayaran sanksi secara materiil yang harus dibayarkan oleh pengusaha sebagai uang ganti kerugian apabila sanksi teguran tertulis tidak diindahkan lagi.

3) Tidak mendapat pelayanan publik tertentu. Sanksi administratif ini termasuk sanksi berat yang diberikan kepada pengusaha yakni berupa tidak mendapat pelayanan publik tertentu apabila kedua sanksi di atas tidak dilaksanakan.

Implementasi program BPJS Ketenagakerjaan harus didukung dan disukseskan dari seluruh elemen yakni pemerintah, 
perusahaan, pemberi kerja yang biasa disebut sebagai pengusaha, serta pekerja atau buruh, yang memiliki andil besar dalam meningkatkan kredibilitas pekerja sehingga dapat menikmati kehidupan yang nyaman dan terjamin.

\subsubsection{Hambatan yang dihadapi dalam implementasi program Badan Penyelenggara Jaminan Sosial Ketenagakerjaan bagi pekerja di TPA Desa Temesi Kabupaten Gianyar}

Berdasarkan Pasal 27 ayat (1) Undang-Undang Dasar Negara Republik Indonesia Tahun 1945 yang menyatakan "Segala warga negara bersamaan kedudukannya dalam hukum dan pemerintahan dan wajib menjunjung hukum dan pemerintahan itu dengan tidak ada kecualinya." Pasal 27 ayat (2) UndangUndang Dasar Negara Republik Indonesia Tahun 1945 menegaskan bahwa "Tiap-tiap warga negara berhak atas pekerjaan dan penghidupan layak bagi kemanusiaan." Pasal 28 D ayat (2) Undang-Undang Dasar Negara Republik Indonesia Tahun 1945 menyatakan "Setiap orang berhak untuk bekerja serta mendapatkan imbalan dan perlakuan yang adil dan layak dalam hubungan kerja." Prinsip yang terkandung dalam ketentuan konstitusional diatas berkaitan erat dengan upaya perlindungan bagi tenaga kerja. Perlindungan hukum bagi rakyat bertumpu pada konsep tentang pengakuan dan perlindungan hak asasi manusia. Perlindungan terhadap tenaga kerja dimaksudkan untuk menjamin hak-hak dasar pekerja/buruh dan menjamin kesamaan kesempatan serta perlakuan tanpa diskriminasi atas dasar apa pun untuk mewujudkan kesejahteraan buruh dan keluarganya dengan tetap memperhatikan perkembangan kemajuan dunia usaha. ${ }^{8}$ Hubungan tenaga kerja dan majikan adalah hubungan

8. I Made Udiana, 2015, Kedudukan dan Kewenangan Pengadilan Hubungan Industrial, Cet. I, Udayana University Press, Denpasar, (selanjutnya disebut I Made Udiana), h. 4. 
hukum yang melahirkan hak dan kewajiban pribadi dalam hidup bermasyarakat. $^{9}$ Demi kesejahteraan para pekerja sudah seharusnya para pekerja mendapat kenyamanan dalam bentuk pemberian jaminan perlindungan guna meningkatkan taraf hidup pekerja menjadi lebih layak. ${ }^{10}$ Adapun hambatan-hambatan yang dihadapi oleh pihak TPA Temesi terkait dengan pengimplementasian program BPJS Ketenagakerjaan ialah sebagai berikut:

1) Bagi pekerja kontrak statusnya masih kurang jelas tidak tentu akan diperpanjang atau tidak masa kerjanya oleh TPA Temesi.

2) Tidak adanya posisi staf yang kosong untuk pekerja kontrak. Dikarenakan masih banyak terdapat pekerja tetap di setiap posisi staf yang masih aktif di TPA Temesi.

3) Bagi pekerja harian lepas yang memiliki masa bekerja selama 1-3 bulan saja, tidak memiliki kepastian kalau masa kerjanya akan diperpanjang atau tidak dikarenakan masih banyaknya terdapat pekerja kontrak maupun pekerja tetap pada posisinya masing-masing di TPA Temesi.

4) Para pekerja masih kurang pengetahuannya dalam memahami pelaksanaan dari program BPJS Ketenagakerjaan di TPA Temesi.

Program BPJS tidak hanya diperuntukkan bagi para pemberi kerja dan pekerja tetapi juga menjadi tugas wajib untuk setiap warga negara agar mendaftarkan dirinya sebagai peserta program BPJS yang berperan sebagai langkah awal untuk perlindungan diri

9. I Made Udiana, 2018, Industrialisasi \& Tanggungjawab Pengusaha terhadap Tenaga Kerja Terlibat Hukum, Cet. I, Udayana University Press, Denpasar, (selanjutnya disebut I Made Udiana II), h. 27.

10. Asri Wijayanti, 2010, Hukum Ketenagakerjaan Pasca Reformasi, Cet. II, Sinar Grafika, Jakarta, h. 122. 
atau proteksi diri sebelum terjadinya kemungkinan terburuk. Setiap hambatan yang dihadapi hendaknya dapat diatasi dengan berbagai upaya yang bisa ditempuh dalam pengimplementasian program BPJS Ketenagakerjaan diantaranya adalah:

1) Dibuatkannya perjanjian kerja untuk pekerja kontrak yang mengatur tentang hak serta kewajiban masingmasing para pihak sekaligus pekerja kontrak diutamakan dalam hal pemberian jaminan dan perlindungan.

2) Pemberian prioritas bagi pekerja kontrak jika terdapat posisi kosong karena pekerja tetap yang keluar dari tempat bekerja.

3) Dibuatkannya perjanjian kerja untuk pekerja harian lepas yang mengatur tentang hak serta kewajiban masing-masing para pihak sekaligus pekerja harian lepas diutamakan dalam hal pemberian jaminan dan perlindungan.

4) Memberikan sosialisasi dari pihak TPA Temesi kepada para pekerja terkait program BPJS Ketenagakerjaan sehingga para pekerja mengetahui bahkan memahami berbagai bentuk perlindungan maupun jaminan yang diatur dalam pogram BPJS Ketenagakerjaan.

\section{PENUTUP}

\subsection{Kesimpulan}

1. Implementasi pendaftaran pekerja sebagai peserta BPJS harus sesuai dengan ketentuan yang berlaku. Walaupun pengimplementasian dari program BPJS Ketenagakerjaan sudah diterapkan di TPA Desa Temesi Kabupaten Gianyar dengan mendaftarkan pekerja sebagai peserta BPJS Ketenagakerjaan yang diperuntukkan bagi pekerja tetap 
serta pekerja kontrak yang ada di lingkungan tempat kerja TPA Temesi dimana pengimplementasiannya sudah sesuai dengan ketentuan peraturan yang berlaku, namun sangat disayangkan karena pekerja harian lepas di TPA Temesi belum terdaftar, maka TPA Temesi belum sepenuhnya menerapkan program pemerintah.

2. Adapun hambatan-hambatan yang dihadapi pihak TPA Temesi dalam merealisasikan pengimplementasian program BPJS Ketenagakerjaan ialah kurangnya kepastian yang diberikan pihak TPA Temesi kepada pekerja kontrak dan pekerja harian lepas akan masa kerja yang tidak tentu akan diperpanjang atau tidak karena masih banyak terdapat pegawai tetap serta kurangnya pemahaman pekerja mengenai program BPJS Ketenagakerjaan.

\subsection{Saran}

1. Pekerja/buruh disarankan agar lebih memahami mengenai program BPJS Ketenagakerjaan dan berperan aktif dalam memastikan pemberi kerja sudah mendaftarkan pekerja/buruh sebagai peserta dalam program BPJS Ketenagakerjaan.

2. Pemberi kerja diharapkan untuk melaksanakan pendaftaran seluruh pekerjanya sebagai peserta program BPJS Ketenagakerjaan sesuai dengan ketentuan peraturan perundang-undangan yang berlaku. Pemerintah juga diharapkan untuk selalu mengawasi pelaksanaan program BPJS sesuai dengan ketentuan peraturan perundang-undangan yang berlaku agar tidak ada pemberi kerja yang belum mendaftarkan pekerjanya. 


\section{DAFTAR PUSTAKA}

\section{BUKU-BUKU}

Amiruddin dan H. Zainal Asikin, 2016, Pengantar Metode Penelitian Hukum, Cet. IX, Rajawali Pers, Jakarta.

Burhan, Ashsofa, 2004, Metode Penelitian Hukum, PT Rineka Cipta, Jakarta.

Fahrojih, Ikhwan, 2016, Hukum Perburuhan: Konsepsi, Sejarah, dan Jaminan Konstitusional, Setara Press, Malang.

Husni, Lalu, 2014, Pengantar Hukum Ketenagakerjaan, Cet. XII, PT Raja Grafindo Persada, Jakarta.

Soedarjadi, 2008, Hukum Ketenagakerjaan di Indonesia, Pustaka Yustisia, Yogyakarta.

Udiana, I Made, 2015, Kedudukan dan Kewenangan Pengadilan Hubungan Industrial, Cet. I, Udayana University Press, Denpasar, (selanjutnya disebut I Made Udiana).

2018, Industrialisasi \& Tanggungjawab Pengusaha terhadap Tenaga Kerja Terlibat Hukum, Cet. I, Udayana University Press, Denpasar, (selanjutnya disebut I Made Udiana II).

Wijayanti, Asri, 2010, Hukum Ketenagakerjaan Pasca Reformasi, Cet. II, Sinar Grafika, Jakarta.

\section{JURNAL ILMIAH}

A.A. Ayu Indah Mahardani, 2017, Perlindungan Hukum Keselamatan Kerja Pekerja Tukang Sapu Pada Dinas Kebersihan dan Pertamanan Kabupaten Badung, Kertha Semaya, Vol. 05, No. 02.

I Ketut Hendra Winata, 2013, Perlindungan Hukum Terhadap Pekerja Setelah Terjadinya Pemutusan Hubungan Kerja 
Secara Sepihak Pada Hotel Four Seasons Resort Bali di Sayan, Kertha Wicara, Vol. 02, No. 01.

\section{PERATURAN PERUNDANG-UNDANGAN}

Undang-Undang Dasar Negara Republik Indonesia Tahun 1945. Berita Republik Indonesia (Tahun 1946) (Lembaran Negara Republik Indonesia Tahun 1959 Nomor 75 dan Lembaran Negara Republik Indonesia Tahun 2006 Nomor 11-14).

Undang-Undang Nomor 13 Tahun 2003 Tentang Ketenagakerjaan.

(Lembaran Negara Republik Indonesia Tahun 2003 Nomor 39, Tambahan Lembaran Negara Republik Indonesia Nomor 4279).

Undang-Undang Nomor 24 Tahun 2011 Tentang Badan Penyelenggara Jaminan Sosial. (Lembaran Negara Republik Indonesia Tahun 2011 Nomor 116, Tambahan Lembaran Negara Republik Indonesia Nomor 5256).

Undang-Undang Nomor 44 Tahun 2015 Tentang Jaminan Kecelakaan Kerja dan Jaminan Kematian. (Lembaran Negara Republik Indonesia Tahun 2015 Nomor 154, Tambahan Lembaran Negara Republik Indonesia Nomor 5714).

Undang-Undang Nomor 45 Tahun 2015 Tentang Program Jaminan

Pensiun. (Lembaran Negara Republik Indonesia Tahun 2015 Nomor 155, Tambahan Lembaran Negara Republik Indonesia Nomor 5715).

Undang-Undang Nomor 46 Tahun 2015 Tentang Program Jaminan Hari Tua. (Lembaran Negara Republik Indonesia Tahun2015 Nomor 156, Tambahan Lembaran Negara Republik Indonesia Nomor 5716). 